\title{
Deleterious Metabolic Effects of High Fructose Intake: The Preventive Effect of Lactobacillus kefiri Administration
}

\author{
María Guillermina Zubiría ${ }^{1,2}$, Sabrina Eliana Gambaro ${ }^{1}$, María Amanda Rey ${ }^{1}$, Paula Carasi ${ }^{3}$, \\ María de los Ángeles Serradell ${ }^{3, *}$ and Andrés Giovambattista ${ }^{1,2, *}$ \\ 1 Neuroendocrinology Laboratory, Multidisciplinary Institute of Cellular Biology (IMBICE, \\ CICPBA-CONICET-UNLP), 52610 y 11, La Plata 1900, Argentina; gzubiria@imbice.gov.ar (M.G.Z.); \\ sabrigambaro@gmail.com (S.E.G.); mamandarey@gmail.com (M.A.R.) \\ 2 Biology Department, School of Exact Sciences, Universidad Nacional de La Plata, La Plata 1900, Argentina \\ 3 Cátedra de Microbiología, Departamento de Ciencias Biológicas, Facultad de Ciencias Exactas, \\ Universidad Nacional de La Plata (UNLP), 47 y 115 s/n, La Plata 1900, Argentina; paulacarasi@gmail.com \\ * Correspondence: maserr@biol.unlp.edu.ar (M.d.l.A.S.); agiovamba@imbice.gov.ar (A.G.)
}

Received: 27 February 2017; Accepted: 3 May 2017; Published: 17 May 2017

\begin{abstract}
Modern lifestyle and diets have been associated with metabolic disorders and an imbalance in the normal gut microbiota. Probiotics are widely known for their health beneficial properties targeting the gut microbial ecosystem. The aim of our study was to evaluate the preventive effect of Lactobacillus kefiri (L. kefiri) administration in a fructose-rich diet (FRD) mice model. Mice were provided with tap water or fructose-added $(20 \% w / v)$ drinking water supplemented or not with L. kefiri. Results showed that probiotic administration prevented weight gain and epidydimal adipose tissue (EAT) expansion, with partial reversion of the adipocyte hypertrophy developed by FRD. Moreover, the probiotic prevented the increase of plasma triglycerides and leptin, together with the liver triglyceride content. Leptin adipocyte secretion was also improved by L. kefiri, being able to respond to an insulin stimulus. Glucose intolerance was partially prevented by L. kefiri treatment (GTT) and local inflammation (TNF $\alpha$; IL1 $\beta$; IL6 and INF $\gamma$ ) was completely inhibited in EAT. L. kefiri supplementation generated an impact on gut microbiota composition, changing Bacteroidetes and Firmicutes profiles. Overall, our results indicate that the administration of probiotics prevents the deleterious effects of FRD intake and should therefore be promoted to improve metabolic disorders.
\end{abstract}

Keywords: gut microbiota; fructose-rich diet; adipose tissue; probiotics

\section{Introduction}

Obesity has been defined by the World Health Organization as an Adipose Tissue (AT) excess that could be harmful to the organism, predisposing to pathologies such as type II Diabetes Mellitus, cardiovascular disease, dyslipidemias, fatty liver disease, and certain cancers. AT mass expansion is associated with serious changes in AT architecture and function, among which adipocyte hypertrophy is one of the most relevant features. Hypertrophic adipocytes are characterized by releasing high amounts of leptin, pro-inflammatory cytokines, low adiponectin, and insulin-resistance [1,2]. Furthermore, AT mass expansion induces a shift from an anti- to pro-inflammatory profile of immune cells resident in this tissue, leading to a general pro-inflammatory state of AT $[3,4]$.

Obesity is a multifactorial disorder caused by the interaction of genetic background and environmental factors, such as altered eating habits [5]. Modern diets are characterized by high carbohydrate intake, especially fructose-sweetened beverages, and have been associated with high prevalence of overweight and Metabolic Syndrome (MS) in humans [6]. High-fructose feeding has 
been widely used in animal models to induce obesity and MS phenotype [7-10]. In the present study, we used a fructose-rich diet intake (FRD, 20\% $w / v$ in drinking water), which is far from fructose intake by humans, to generate a mice model of obesity. Previously, FRD has been related to the development of insulin resistance, dyslipidemias, increased abdominal AT mass, and changes in the pattern of AT adipokine secretion $[7,8,11]$. Partly, these metabolic disorders are a consequence of fructose-induced hepatic de novo lipogenesis, and the resulting increase in AT fatty acid uptake [12,13].

Gut microbiota is composed of 1 to 10 trillion microorganisms, mainly bacteria, among which approximately $90 \%$ belong to the Bacteroidetes, Firmicutes, Actinobacteria and Proteobacteria phyla [14]. Symbiotic relationships between bacteria and their hosts modulate several physiological processes such as nutrients uptake, metabolism, and immune response, among others [15]. Environmental factors such as diet, treatment with antibiotics, and exercise can modulate gut microbiota composition. Obesity has been associated with gut microbiota dysbiosis, contributing to the establishment of characteristic alterations related to obesity. Since transplantation of lean gut microbiota to obese mice can rescue the obese phenotype [16], strategies to manipulate the composition of the gut microbiota have gained considerable importance for metabolic pathologies management. Probiotics are defined as live microorganisms that, when administered, exert positive health effects in the host. It is largely accepted that probiotics are involved in the maintenance of healthy gut microbiota, and for this reason their use has emerged as a potential therapy against MS and obesity [17].

Kefir is a food product obtained by fermentation of milk with "kefir grains". These grains are constituted by a complex symbiotic microbiota, mainly of yeast, lactic acid, and acetic acid bacteria confined in a matrix of polysaccharides and proteins $[18,19]$. Several health-promoting properties have been associated with kefir consumption $[19,20]$, and the study of the beneficial properties of kefir-isolated microorganisms can be considered as a very important field for the development of functional foods. Lactobacillus kefiri is one of the most important lactobacilli obtained from kefir grains [21,22]. Different in vitro studies have revealed that secretion products and surface proteins from different $L$. kefiri strains can exert a protective action against intestinal pathogens such as Salmonella enterica [23] and Clostridium difficile [24]. Moreover, Carey and Kostrzynska reported that $L$. kefiri attenuates the pro-inflammatory response in intestinal epithelial cells induced by Salmonella typhimurium, and Hong et al. showed its influence on Th1 and pro-inflammatory cytokine production in macrophages [25,26].

Recent studies have demonstrated that L. kefiri CIDCA 8348 strain resists passage through simulated gastrointestinal conditions [27] and its oral administration is safe to mice [28]. Interestingly, mice treated with L. kefiri CIDCA 8348 showed a down-regulation of the gene expression of pro-inflammatory mediators and an up-regulation of anti-inflammatory molecules, secreted IgA and mucins in the gut [29]. Based on this evidence, we aimed to evaluate the preventive effect of L. kefiri CIDCA 8348 administration on the metabolic alterations caused by FRD in mice.

\section{Material and Methods}

\subsection{Bacterial Strain and Growth Conditions}

A kefir-isolated Lactobacillus kefiri strain (CIDCA 8348, L. kefiri) [30] from the collection of the “Centro de Investigación y Desarrollo en Criotecnológico de Alimentos" (La Plata, Argentina) was used for experiments. The strain was cultured in MRS-broth (DIFCO, Detroit, MI, USA) at $37^{\circ} \mathrm{C}$ for $48 \mathrm{~h}$ under aerobic conditions. Frozen stock cultures were stored at $-80^{\circ} \mathrm{C}$ in skim milk until use.

\subsection{Animals and Treatment}

Normal adult male Swiss mice (four months of age, $n=15$ mice per group) were kept in a temperature-controlled environment $\left(20-22{ }^{\circ} \mathrm{C}\right.$ and fixed $12 \mathrm{~h}$ light/12 $\mathrm{h}$ dark cycle, lights on at 07:00 a.m.) and fed ad libitum with Purina commercial rat chow. Mice were divided into two groups: one was provided with tap water and the other with a $20 \%$ fructose solution $(w / v$, Sigma-Aldrich, 
St. Louis, MO, USA) added to tap water for 6 weeks (conventionally called fructose rich diet, FRD). Each group was randomly divided and administered L. kefiri $\left(10^{8}\right.$ CFU dissolved in milk; CTR-Lk and DRF-Lk groups) or milk alone (CTR and FRD groups) by oral gavage every $48 \mathrm{~h}$ during the 6-week diet. Food intake and body weight were measured every $48 \mathrm{~h}$. On experimental day, mice were euthanized under non-fasting conditions (between 08:00 a.m. and 09:00 a.m.) and trunk blood was collected; plasma samples were then frozen $\left(-20^{\circ} \mathrm{C}\right)$ until metabolite measurements (Section 2.3). Inguinal AT (IAT, subcutaneous depot), Epididymal AT (EAT, visceral depot) and Retroperitoneal AT (RPAT, visceral depot) were aseptically dissected and weighed. EAT was kept in sterile Dulbecco's Modified Eagle's Medium-Low Glucose (1 g/L) (DMEM-LG) for further procedures. Animals were euthanized according to protocols for animal use, in agreement with National Institutes of Health $(\mathrm{NIH})$ guidelines for the care and use of experimental animals. All experiments were approved by our Institutional Animal Care Committee (approval code 020916).

\subsection{Peripheral Metabolite Measurements}

Non-fasting plasma levels of leptin (LEP, $n=15$ ) were determined by specific radioimmunoassays (RIAs) previously developed in our laboratory [31]. Non-fasting plasma levels of glucose (Glu, $n=15$ ) and triglycerides ( $\mathrm{Tg}, n=15$ ) were measured using commercial kits (Wiener Lab., Rosario, Argentina).

\subsection{EAT Adipocyte Isolation and Incubation}

Fresh EAT pads were dissected, weighed and digested with collagenase as previously reported [32]. Briefly, fat tissue was minced and digested using $1 \mathrm{mg} / \mathrm{mL}$ collagenase solution in DMEM (at $37^{\circ} \mathrm{C}$, for $1 \mathrm{~h}$ ). After centrifugation (1000 rpm for $15 \mathrm{~min}$ ), floating mature adipocytes were separated and diluted up to a density of approximately 200,000 cells per $900 \mu \mathrm{L}$ DMEM-1\% BSA. Adipocytes were distributed in 24 multi-well plates and incubated for $45 \mathrm{~min}$ at $37^{\circ} \mathrm{C}$ in a $5 \%$ $\mathrm{CO}_{2}$ atmosphere with medium alone (basal) or medium containing $10 \mathrm{nM}$ insulin (Novo Nordisk Pharma AG, Küsnacht, Switzerland) [33]. After incubation, medium was carefully aspirated and kept frozen $\left(-20^{\circ} \mathrm{C}\right)$ until measurement of LEP concentrations as described above $(n=6$ independent experiments).

\subsection{EAT Pad Histology}

For histological studies, freshly dissected EAT pads ( $n=4$ per group) were fixed in $4 \%$ paraformaldehyde, then washed with tap water, immersed in a series of graded ethanol solutions ( $70 \%, 96 \%$ and $100 \%)$, and clarified in xylene before paraffin embedding [34]. Four-micrometer sections were taken from different levels of the blocks and stained with hematoxylin-eosin. Quantitative morphometric analysis was performed using a RGB CCD Sony camera and Image Pro-Plus 4.0 software (Image ProPlus6.0, Rockville, MD, USA). For each tissue sample, seven sections and three levels were selected. Systematic random sampling was used to select 15 fields for each section (magnification, $\times 400)$ and 2500 cells per group were examined. Adipocyte area was measured.

\subsection{Glucose Tolerance Test (GTT)}

Four days before the end of the protocol, six mice from each experimental group were fasted for $10 \mathrm{~h}$ (from 10:00 p.m. to 8:00 a.m.) and then glucose $(2 \mathrm{mg} / \mathrm{kg} \mathrm{BW})$ was administered via intraperitoneal (IP) injection. Blood was collected by the tail cut method. Glucose was measured at 0, 30, 60 and 120 min after glucose challenge by one-touch glucometer (Accu-Chek Performa, Roche, Mannheim, Germany). Area under the curve was calculated using Graph Pad Prism 6.0 (GraphPad Software Inc., San Diego, CA, USA). 


\subsection{Liver Lipid Content}

Fifty $\mathrm{mg}$ of the liver ( $n=6$ per group) was homogenized in a $5 \%$ solution of $500 \mu \mathrm{L}$ Triton $\mathrm{X}-100$ in phosphate-buffered saline (PBS). The homogenate was incubated at $80-100{ }^{\circ} \mathrm{C}$ for $5 \mathrm{~min}$ and centrifuged at $10,000 \times g$ for $10 \mathrm{~min}$. Triglyceride $(\mathrm{Tg})$ was measured in the supernatants using a commercial kit (Wiener Lab, Rosario, Argentina).

\subsection{RNA Isolation and Quantitative Real-Time PCR ( $q R T-P C R)$}

Total RNA from EAT ( $n=6$ per group) was isolated by the Trizol extraction method (Invitrogen, Life Tech., Carlsbad, CA, USA) and reverse-transcribed using random primers (250 ng) and RevertAid Reverse Transcriptase (200 U/ $\mu \mathrm{L}$, Thermo Scientific, Vilnius, Lithuania). Two $\mu \mathrm{L}$ cDNA were amplified with HOT FIRE Pol EvaGreenqPCR Mix Plus (Solis BioDyne, Tartu, Estonia) containing $0.5 \mu \mathrm{M}$ of each specific primer, using a Rotor Gene Q (Qiagen, Hilden, Germany). Polymerase chain reaction (PCR) efficiency was near 1 . Expression levels were analyzed for $\beta$-actin (ACT $\beta$, reporter gene), Adiponectin (Adipo), Leptin (Ob), Lipoprotein Lipase (LPL), Fatty Acid Synthase (FAS), Hormone Sensitive Lipase (HSL), Adipose Triglyceride Lipase (ATGL), Tumor Necrosis Factor $\alpha$ (TNF $\alpha)$, Interleukin $1 \beta$ (IL1 $\beta$ ), Interleukin 6 (IL6), and Interferon $\gamma$ (IFN $\gamma)$. Designed primers are shown in Table 1. Relative changes in the expression level of one specific gene $\left(\Delta \Delta C_{t}\right)$ were calculated by the $\Delta C_{t}$ method.

Table 1. Primers used for real time PCR analysis.

\begin{tabular}{|c|c|c|c|}
\hline Gene & Sequence $\left(5^{\prime}-3^{\prime}\right)$ & GBAN & Size Product (bp) \\
\hline ACT $\beta$ & $\begin{array}{l}\text { Fw: TTTGCAGCTCCTTCGTTGCC } \\
\text { Rv: ACCCATTCCCACCATCACAC }\end{array}$ & NM_007393.5 & 189 \\
\hline $\mathrm{Ob}$ & $\begin{array}{l}\text { Fw: ACCAGGATCAATGACATTTCACAC } \\
\text { Rv: GGCTGGTGAGGACCTGTTGA }\end{array}$ & NM_008493.3 & 148 \\
\hline Adipo & $\begin{array}{l}\text { Fw: GGAACTTGTGCAGGTTGGATG } \\
\text { Rv: CCCTTCAGCTCCTGTCATTCC }\end{array}$ & NM_009605.5 & 171 \\
\hline LPL & $\begin{array}{l}\text { Fw: AGGACCCCTGAAGACAC } \\
\text { Rv: GGCACCCAACTCTCATA }\end{array}$ & NM_008509.2 & 149 \\
\hline ATGL & $\begin{array}{l}\text { Fw: CCACTCACATCTACGGAGCC } \\
\text { Rv: AATCAGCAGGCAGGGTCTTC }\end{array}$ & NM_001163689.1 & 198 \\
\hline HSL & $\begin{array}{l}\text { Fw: AGTTACCATCTCACCTCC } \\
\text { Rv: CTTGCTGTCCTGTCCTTC }\end{array}$ & NM_010719.5 & 94 \\
\hline FAS & $\begin{array}{l}\text { Fw: CAAGCAGGCACACACAATGG } \\
\text { Rv: GCCTCGGAACCACTCACA }\end{array}$ & NM_007988.3 & 141 \\
\hline $\mathrm{TNF} \alpha$ & $\begin{array}{c}\text { Fw: CATCTTCTCAAAATTCGAGTGACAA } \\
\text { Rv: CCTCCACTTGGTGGTTTGCT }\end{array}$ & NM_013693.3 & 63 \\
\hline $\mathrm{IFN} \gamma$ & $\begin{array}{c}\text { Fw: TGGCATAGATGTGGAAGAAAAGAG } \\
\text { Rv: TGCAGGATTTTCATGTCACCAT }\end{array}$ & NM_008337.4 & 81 \\
\hline IL1 $\beta$ & $\begin{array}{l}\text { Fw: CTTGTGCAAGTGTCTGAA } \\
\text { Rv: AGGTCAAAGGTTTGGAAG }\end{array}$ & NM_008361.4 & 143 \\
\hline IL6 & $\begin{array}{l}\text { Fw: GTTCTCTG GAAATCGTGGAAA } \\
\text { Rv: AAGTGCATCATCGTTGTTCATACA }\end{array}$ & NM_031168.2 & 77 \\
\hline
\end{tabular}

Specific primers used for real time PCR analyses; Fw: Forward, Rv: Reverse; GBAN: GenBank Accession Number; bp: base pairs.

\subsection{Leptin Measurement}

Medium LEP concentration was determined by specific RIA [35]. In this assay, the standard curve ranged between 50 and $12,500 \mathrm{pg} / \mathrm{mL}$, with intra- and inter-assay variation coefficients of $4-6 \%$ and $5-8 \%$, respectively. 


\subsection{Microbiota Analysis in Feces}

Fecal samples were collected at the end of the experimental protocol and were stored at $-80^{\circ} \mathrm{C}$ prior to use for microbiota analysis. DNA extraction was performed using the AccuPrep Stool DNA Extraction Kit (Bioneer, Daejeon, Korea) according to the manufacturer's instructions.

\subsubsection{Quantitative PCR of Microbiota Populations}

Quantification of bacterial populations was carried out using primers synthesized by Genbiotech (Buenos Aires, Argentina). Primer sequences were previously described [29,36]. PCR reactions were performed in a Rotor Gene Q (Qiagen, Hilden, Germany) using HOT FIRE Pol EvaGreenqPCR Mix Plus (Solis BioDyne, Tartu, Estonia). Twenty ng DNA and $0.2 \mu \mathrm{mol} \mathrm{L}{ }^{-1}$ of each primer were used in PCR mix. A negative control reaction without template was included for each primer combination. Melting curve was conducted from $70{ }^{\circ} \mathrm{C}$ to $90^{\circ} \mathrm{C}$, read every $0.5^{\circ} \mathrm{C}$ during $2 \mathrm{~s}$. For standard curves we used PCR products generated from a pool of purified genomic DNA from the different samples and the primers previously described $[29,36]$. Results were expressed as number of copies/g wet weight feces.

\subsubsection{Qualitative Analysis by PCR-DGGE}

Primers 518r (5'-ATTACCGCGGCTGCTGG-3') and 338f (5'-CTCCTACGGGAGGCAGCAG-3') coupled to a 50-GC clamp [37], targeting the V3 region of the 16S rRNA subunit [38], were used to assess microbial diversity in each sample. PCR was performed in a Stratagene Gradient Cycler (Agilent Technologies Inc., Philadelphia, PA, USA) using 1 U of PFU DNA Polymerase (PB-L, EmbioTec SRL, Buenos Aires, Argentina) per 50 pg of DNA template. The PCR products were separated in $8 \%$ polyacrylamide gels (37.5:1 acrylamide:bisacrylamide) with a range of 40-60\% denaturing gradient (100\% denaturant consisted of $7 \mathrm{M}$ urea and $40 \%$ deionized formamide) cast in a DDGE-2401 device (C.B.S Scientific Co., Del Mar, CA, USA). The electrophoresis was performed in TAE 0.5X buffer for $16 \mathrm{~h}$ at a constant voltage of $100 \mathrm{v}$ and a temperature of $60^{\circ} \mathrm{C}$. Gels were stained with SYBR Gold $0.01 \mu \mathrm{L} / \mathrm{mL}$ (Invitrogen, Life Technologies, Carlsbad, CA, USA) in TAE 1X buffer and visualized in a Bio-Rad Universal Hood II gel documentation system (Bio-Rad laboratories Inc., Hercules, CA, USA). PyElph 1.4 software was used to calculate the dendrograms using the UPGMA (unweighted pair group method with arithmetic mean clustering algorithm) [39].

\subsection{Statistical Analysis}

Results are expressed as mean values \pm S.E.M. Data were analyzed by ANOVA (one-way) method followed by Fisher's test. Body weight data were analyzed using a multivariate test (IBM SPSS statistics 22, IBM Corp., New York, NY, USA). To determine the differential effect of the treatments, ANOVA (two-way) analysis was performed followed by Tukey's test. $p$ values lower than 0.05 were considered statistically significant. All statistical tests were performed using GraphPad Prism 6.0 (GraphPad Software Inc., San Diego, CA, USA).

\section{Results}

\subsection{L. kefiri Administration Prevents Body Weight Gain and AT Expansion}

Caloric intake for FRD mice was higher than that for CTR mice (Figure 1A; $P<0.05$ ) and, as expected, was accompanied by an increase in body weight (Figure $1 \mathrm{~B} ; P<0.05$ vs. CTR). L. kefiri administration to CTR mice (CTR-Lk group) did not modify caloric intake or body weight compared to CTR animals. However, administration of $L$. kefiri during FRD intake prevented the increase in body weight without changing the caloric intake $(P<0.05$ vs. FRD). Multivariate analysis showed an interaction between diet and probiotic administration had a significant effect $(P=0.02)$. FRD consumption has been widely used in animal models to induce metabolic disorders as those observed 
in human MS; one of these features is the visceral AT expansion. Our results showed that FRD induced a significant increase in EAT mass $(P<0.05)$. Interestingly, probiotic treatment inhibited EAT mass expansion induced by FRD intake (FRD-Lk mice; $P<0.05)$ and also decreased EAT mass in CTR-Lk mice compared to CTR (Figure $1 C ; P<0.05$ ). With regard to other AT depots studied, although no significant differences were found among experimental groups, FRD mice showed a trend toward increased IAT and RPAT mass, which was not observed in FRD-Lk mice (Figure 1D,E).

Unhealthy AT expansion has been associated with hypertrophic adipocytes while hyperplastic AT expansion prevents AT dysfunctions. Histological analysis of adipocyte size from EAT showed that L. kefiri administration did not affect cell size in CTR-Lk mice (Figure 1F). On the other hand, FRD induced an increase in adipocyte size $(P<0.01)$ that was not observed in FRD-Lk adipocytes. Thus, high fructose consumption generated an unhealthy EAT expansion but was partially prevented by the probiotic treatment.

A

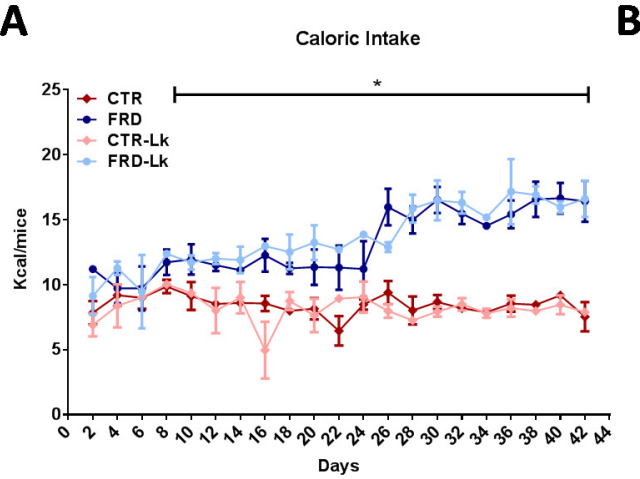

C

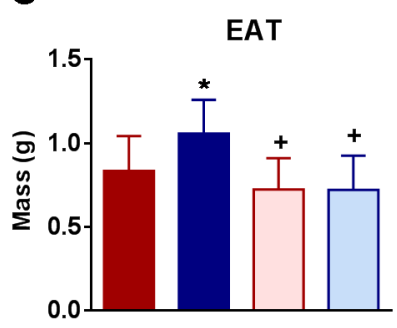

D

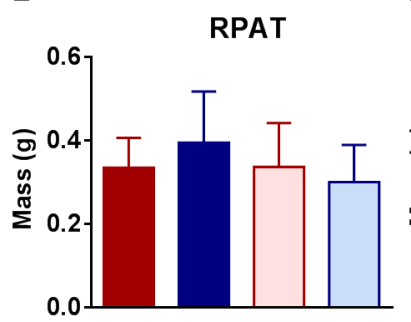

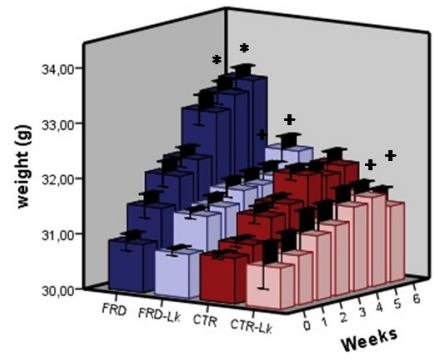

E

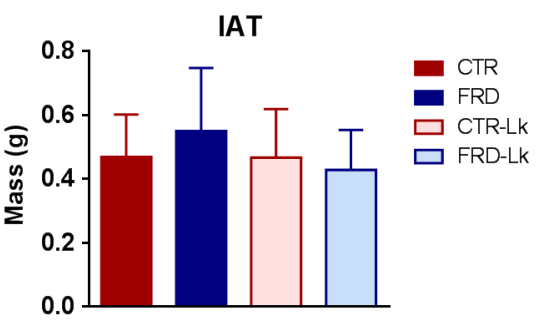

F

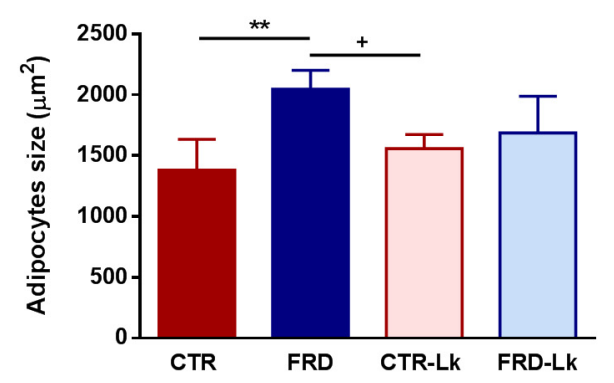

G

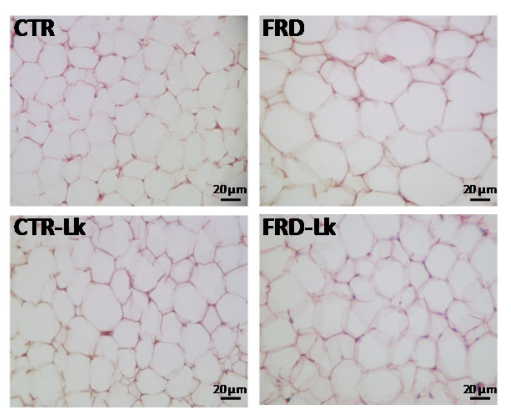

Figure 1. Mean of caloric intake, body weight and AT expansion. (A) Caloric intake $\left({ }^{*} P<0.05\right.$ vs. CTR and CTR-Lk) and (B) body weight from the different groups. $\left({ }^{*} P<0.05\right.$ vs. CTR. ${ }^{+} P<0.05$ vs. FRD) (C) EAT, (D) RPAT and (E) IAT mass were measured. ${ }^{*} P<0.05$ vs. CTR and ${ }^{+} P<0.05$ vs. FRD. ( $n=15$ mice per group). (F) EAT adipocyte size. ( $n=4$ mice per group). ${ }^{*} P<0.001 \mathrm{vs.} \mathrm{CTR}$ and $^{+} P<0.05$ vs. FRD. (G) Representative EAT histological samples stained with hematoxylin-eosin. Values are means \pm SEM. 


\subsection{Metabolic Alterations and Glucose Homeostasis Impairment Were Improved by Probiotic Treatment}

FRD mice showed an impaired metabolic profile, characterized by higher plasmatic concentration of $\mathrm{Tg}$ and LEP than CTR mice, without changes in Glu plasmatic levels (Figure $2 \mathrm{~A}-\mathrm{C} ; P<0.05$ and $P<0.01$, respectively). L. kefiri treatment did not modify these parameters in CTR-Lk mice. Interestingly, FRD-Lk mice showed circulating levels of Tg and LEP similar to CTR mice, which reveals the beneficial effect of L. kefiri administration on the metabolic profile from high-fructose feeding mice.

Additionally, liver lipid content was similar for CTR and CTR-Lk mice (Figure 2D). As expected, considering the strong lipogenic capacity of fructose, FRD mice showed higher liver lipid levels $(P<0.05)$. This increase was in part attenuated by the administration of L. kefiri (FRD-Lk group).

GTT was performed to assess glucose homeostasis in the different groups. Administration of L. kefiri to CTR mice did not modify GTT response, as shown in Figure 2E. For the case of FRD group, we observed an impaired glucose tolerance, which was clearly evidenced in a higher area under the curve (Figure 2F; $P<0.05$ ). This glucose intolerance was partially prevented by L. kefiri treatment (FRD-Lk).

A

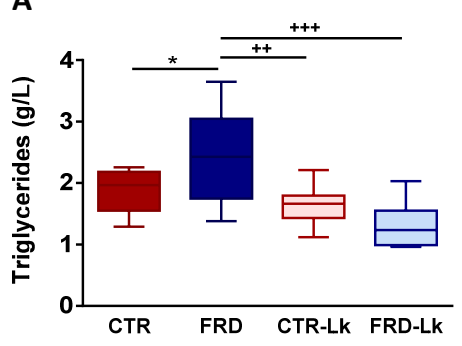

C

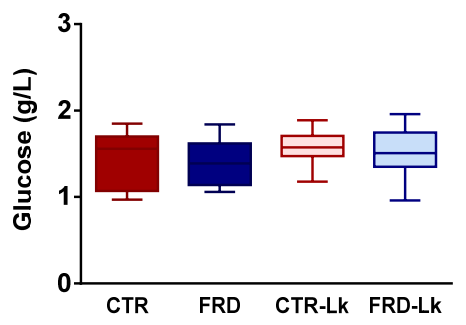

B

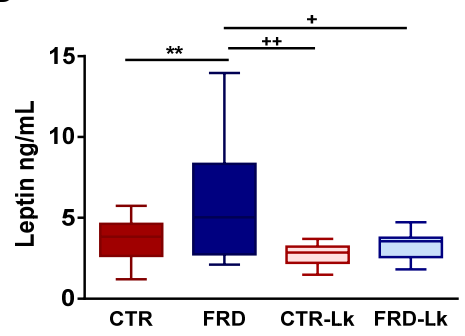

D

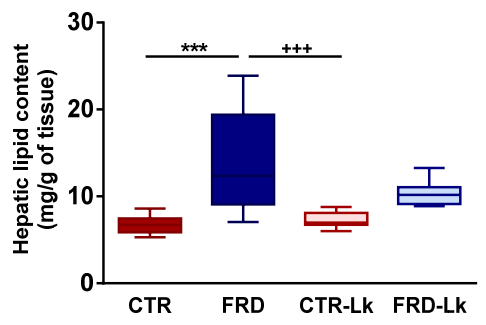

$\mathbf{F}$

E

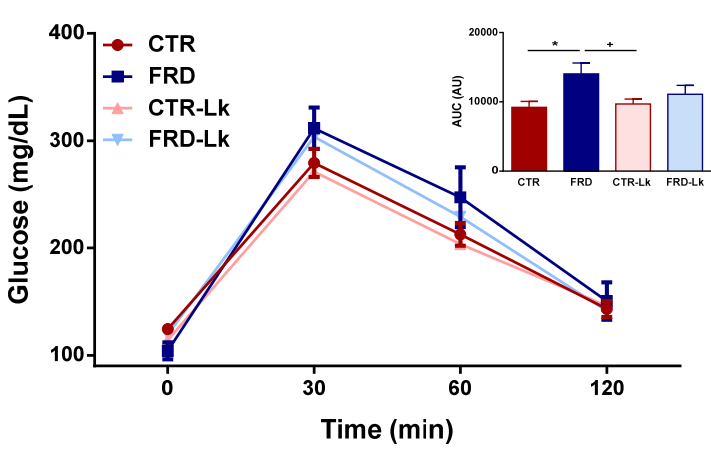

Figure 2. Metabolic Parameters and Glucose Tolerance Test. (A) Triglycerides, (B) Leptin and (C) Glucose plasma concentrations were recorded. ( $n=15$ mice per group). (D) Liver triglycerides content was assessed in the four groups. Values are means \pm range ( $n=6$ mice per group). (E) GTT was performed four days before to the end of the protocol. Glucose concentration was measured at 0, 30, 60 and $120 \mathrm{~min}$ after glucose challenge. (F) Area under the curve was calculated. Values are means \pm SEM ( $n=6$ mice per group). ${ }^{*} P<0.05 ;{ }^{* *} P<0.01$ and ${ }^{* * *} P<0.001$ vs. CTR. ${ }^{*} P<0.05 ;^{++} P<0.01$ and ${ }^{+++} P<0.001$ vs. FRD. 


\subsection{L. kefiri Administration Reduces EAT Dysfunctions Induced by FRD}

AT dysfunction directly correlates with adipocyte size. Hypertrophic adipocytes are insulin resistant and secrete an altered adipokyne pattern (LEP and Adipo) and pro-inflammatory cytokines. As shown in Figure 3A,B, isolated EAT adipocytes from CTR-Lk secreted similar amount of LEP as CTR mice, both spontaneously and after insulin stimulation. FRD hypertrophic adipocytes secreted more LEP than CTR ones, and did not respond to insulin stimulus $(P<0.0001$ and $P<0.0001$ vs. CTR, respectively). Under basal condition, adipocytes from FRD-Lk showed an intermediate secretion of LEP between CTR and FRD adipocytes, suggesting a partial protection exerted by L. kefiri administration on the impairment of LEP secretion caused by FRD. Interestingly, when FRD-Lk adipocytes were insulin-stimulated, they significantly increased their LEP release $(P<0.001$ vs. FRD-Lk basal), indicating insulin sensitivity recovery $(P<0.05$ vs. FRD).

When mRNA expression was analyzed, EAT from FRD expressed significantly higher LEP levels than CTR adipocytes (Figure 3C; $P<0.01$ ), while L. kefiri administration protected FRD-Lk mice from this increase (Figure 3C; $P<0.001$ vs. FRD), in agreement with results detailed above. Neither FRD nor L. kefiri treatment altered adiponectin mRNA levels. To assess the status of lipid metabolism in EAT we evaluated the expression of different enzymes involved in lipolysis/lipogenesis pathway. As shown in Figure 3D, EAT from FRD mice expressed higher mRNA levels of HSL and LPL than CTR (HSL: $P<0.05$ and LPL: $P<0.05$ ) and CTR-Lk mice (HSL: $P<0.05$ and LPL: $P<0.01$ ), whereas Lk administration to FRD mice prevented this increase (HSL: $P<0.05$ and LPL: $P<0.01$ vs. FRD).

A

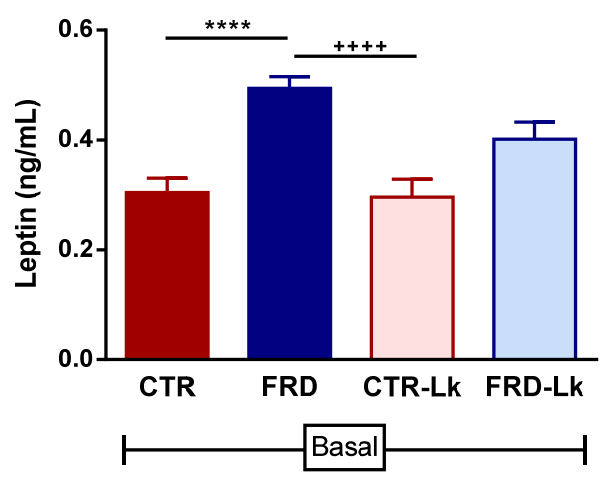

B

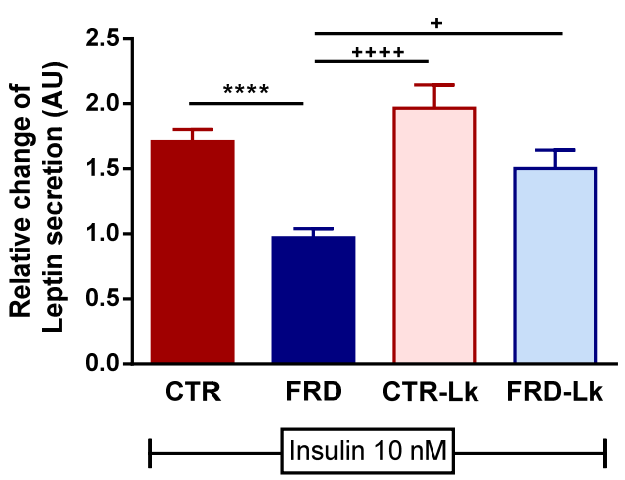

C

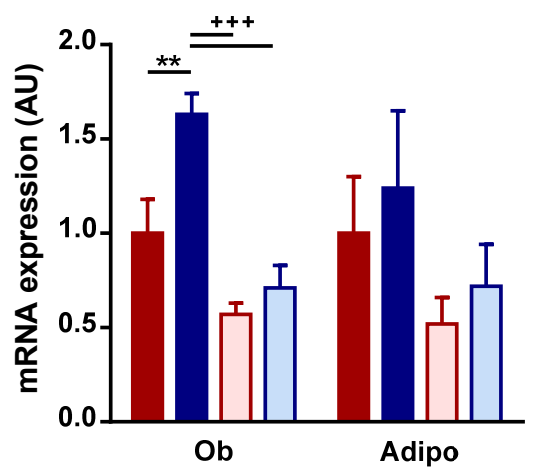

D

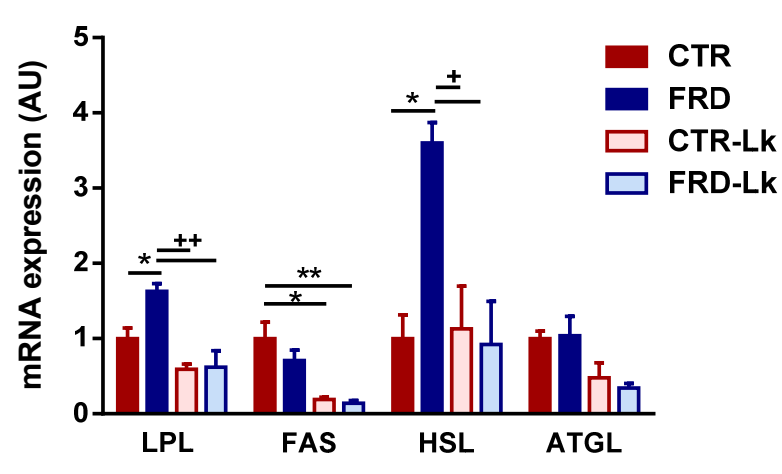

Figure 3. Improvement of EAT function. (A) Leptin secretion from cultured adipocytes in basal conditions. (B) Relative change of leptin secretion after insulin stimulus compared to basal secretion for each group. ( $n=6$ independent experiments). EAT mRNA expression of (C) LEP (Ob) and adiponectin (Adipo) and (D) lipid metabolism-related enzymes (LPL, HSL, ATGL, FAS). ( $n=6$ mice per group). Values are means \pm SEM. ${ }^{*} P<0.05 ;{ }^{* *} P<0.01$ and ${ }^{* * * *} P<0.0001$ vs. CTR. ${ }^{+} P<0.05 ;{ }^{++} P<0.01$; ${ }^{+++} P<0.001$ and $^{++++} P<0.0001$ vs. FRD. 


\subsection{L. kefiri Treatment Protects EAT from Inflammation Induced by FRD}

It is well known that obesity is associated with AT chronic inflammatory state caused by the change of AT resident immune cells from anti-inflammatory Type 2 to pro-inflammatory Type 1, favoring insulin-resistance. In this regard, our results showed that FRD intake induced an inflammatory state in EAT, evidenced by significant increase of IL6, IL1 $\beta$, TNF $\alpha$ and IFN $\gamma$ expression (Figure 4; $P<0.05$ vs. CTR), that was prevented by $L$. kefiri treatment (IFN $\gamma: P<0.05$; IL1 $\beta$ : $P<0.01$ and IL6: $P<0.01$ vs. FRD). Noticeably, we found that $L$. kefiri administration did not modify mRNA levels of pro-inflammatory cytokines in EAT from CTR-Lk mice.

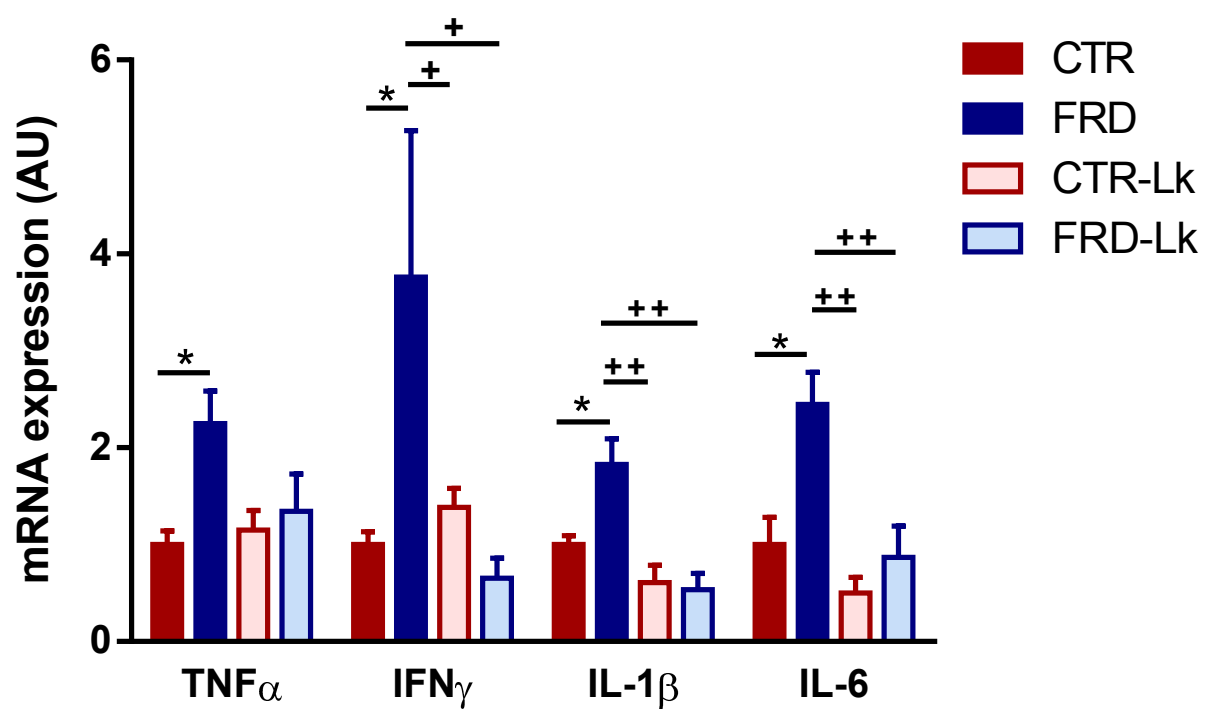

Figure 4. Inflammatory profile of EAT. Gene expression of pro-inflammatory cytokines (TNF $\alpha$, INF $\gamma$, IL1 $\beta$, IL6) in EAT from the four experimental groups. Values are means $\pm \operatorname{SEM}$ ( $n=6$ mice per group). ${ }^{*} P<0.05$ vs. CTR. ${ }^{+} P<0.05$ and ${ }^{++} P<0.01$ vs. FRD.

\subsection{Effects of FRD and L. kefiri Administration on Gut Microbiota Composition}

To study the effects of diet and probiotic administration on gut microbiota structure, we analyzed the fecal bacterial composition by PCR-DGGE and qPCR. Both FRD and Lk administration produced qualitative changes in the microbial community composition, since the cluster analysis based on the Pearson product-moment correlation coefficient and UPGMA linkage allowed differentiation of the experimental groups in separated clusters (Figure 5), without differences in the number of amplification bands generated from each sample (not shown). Regarding qPCR assays, we performed two-way ANOVA analysis to determine if FRD or Lk or the interaction of both variables have some effect on fecal bacterial amounts. Firstly, no differences in the total number of bacteria between groups were found, although a trend to increase was observed in mice under probiotic treatment, independently of diet intake (Table 2). When specific bacterial phyla were analyzed, we found a different effect regarding diet and probiotic administration. FRD feeding decreased the Lactobacillus spp. (Figure 6A, $P=0.015)$ and increased Bacteroides fragilis quantities independently of probiotic administration (Figure 6B, $P=0.0074$ ). On the other hand, when L. kefiri administration was analyzed we found an increase in Firmicutes and Bacteroidetes phyla (Figure 6A, $P=0.007$ and $P=0.027$ respectively), and in Lactobacillus murinus and Bacteroides fragilis species (Figure 6B, $P=0.0048$ and $P=0.0072$ respectively), in spite of mice receiving or not the FRD. No differences were found in L. acidophilus group when both variables were analyzed. 


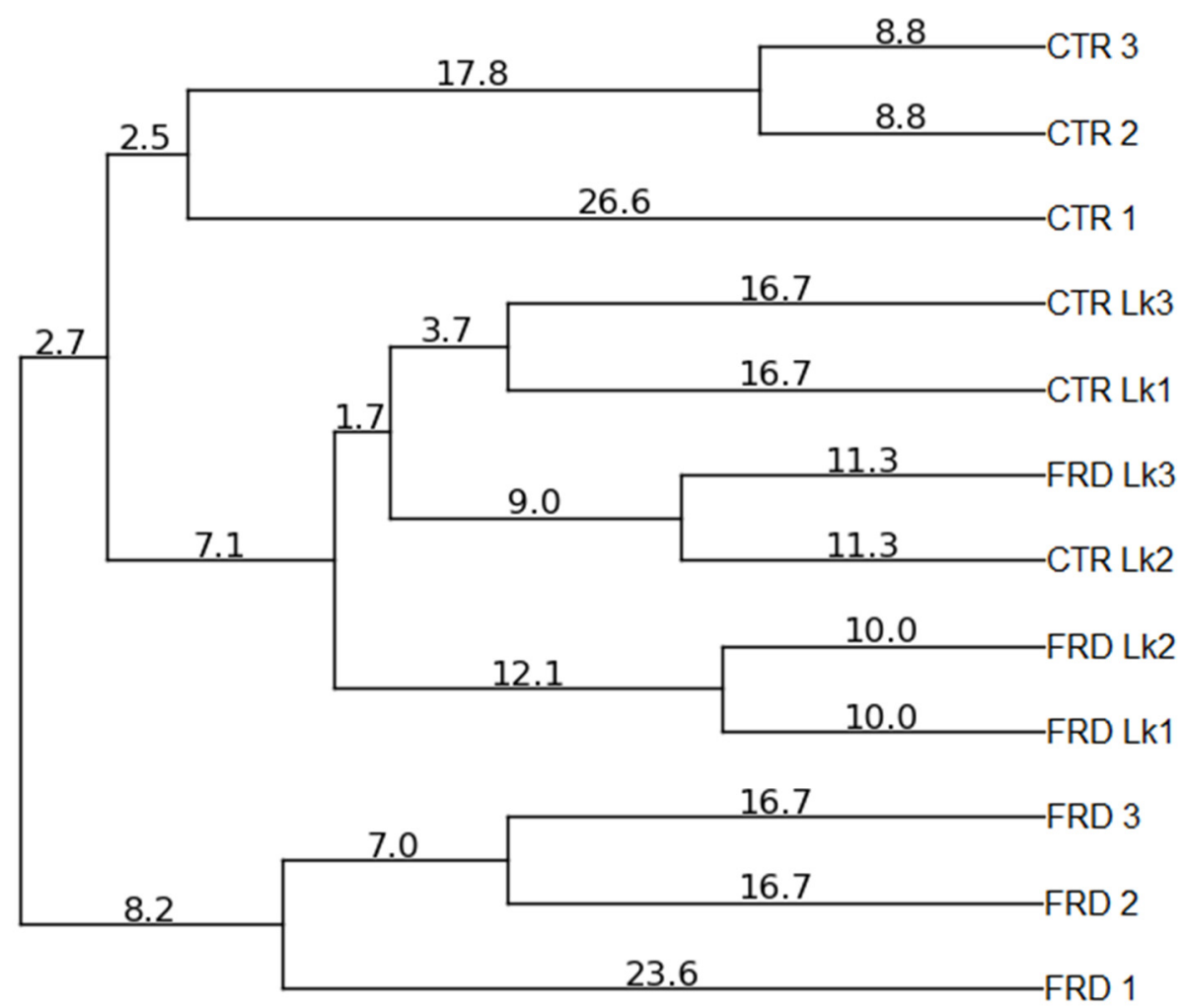

Figure 5. Qualitative analysis of fecal microbiota profile. Dendrogram for the total bacterial DGGE profiles. Clustering analysis was performed using the UPGMA linkage.

Table 2. Total bacteria quantification in feces.

\begin{tabular}{ccccc}
\hline & CTR & FRD & CTR-Lk & FRD-Lk \\
\hline $\begin{array}{c}\text { Total Bacteria }(N \text { of } \\
\text { copies/g of feces) }\end{array}$ & $3.73 \times 10^{9} \pm 5.6 \times 10^{8}$ & $4.97 \times 10^{9} \pm 5.0 \times 10^{8}$ & $5.94 \times 10^{9} \pm 6.7 \times 10^{8}$ & $6.97 \times 10^{9} \pm 7.8 \times 10^{8}$ \\
\hline
\end{tabular}

After the overall variable analyses, we compared the microbiota composition among the different groups. Interestingly, we found that Bacteroidetes population from FRD-Lk mice was significantly increased compared to CTR $(P<0.05)$. Accordingly, Bacteroides fragilis (Bacteroidetes phylum) was also increased in FRD-Lk $(P<0.05$ vs. CTR and FRD) and in CTR-Lk mice $(P<0.05$ vs. CTR). Additionally, Lactobacillus murinus was also more abundant in FRD-Lk and in CTR-Lk $(P<0.05)$ than their counterparts without probiotic administration (Figure 6B). These changes in the microbiota composition in Lk-treated mice could suggest the presence of a healthier microbiota, which could be related to the beneficial metabolic changes found in them. 

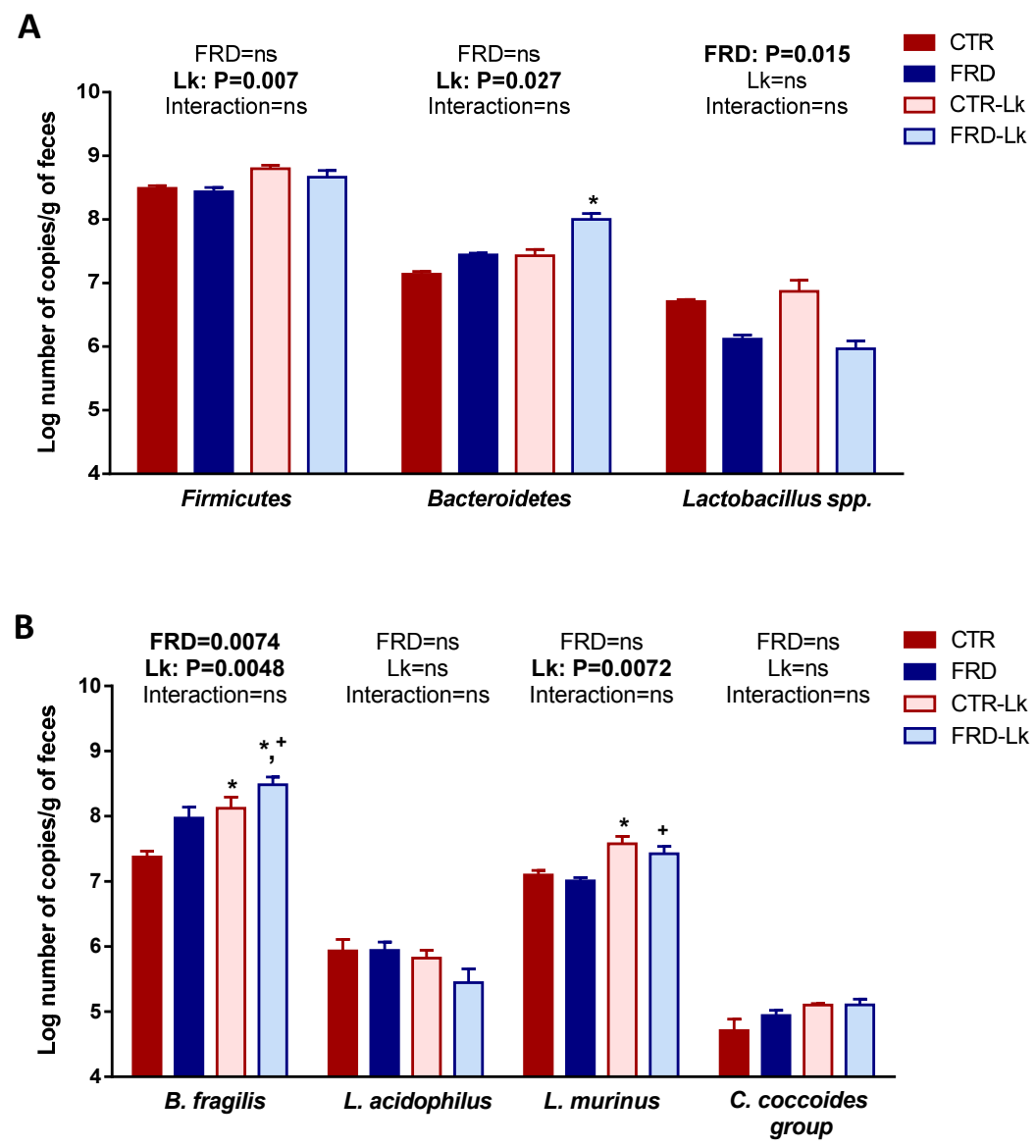

Figure 6. Analysis of microbiota composition in feces. (A) Lactobacillus spp., Lactobacillus acidophilus (L. acidophilus) and Lactobacillus murinus (L. murinus) quantification. (B) Firmicutes and Bacteroidetes phyla, Clostridium coccoides group (C. coccoides group) and Bacteroides fragilis (B. fragilis) quantification. Two-way ANOVA was performed for variable analysis and Tukey's multiple comparisons post-test was performed for group-to-group comparisons. ns $=$ no significant differences. Values are means $\pm \operatorname{SEM}\left(n=3\right.$ mice per group) ${ }^{*} P<0.05$ vs. CTR, ${ }^{+} P<0.05$ vs. FRD.

\section{Discussion}

Over the few last decades, the importance of the symbiotic relationship between gut microbiota and host in energy absorption, immune system and metabolism has been described [40]. Alterations caused by environmental factors on gut microbiota composition could lead to host metabolic disorders, as has been observed in both obese humans and rodents [41-43]. Since probiotics modulate gut microbiota and also affect host metabolism, the use of probiotics has been associated with several metabolic improvements in obese phenotypes $[40,44]$. In this regard, several studies have demonstrated the benefits of the use of lactobacilli as probiotics, improving liver pathologies, among others $[45,46]$.

Fructose-sweetened beverages are one of the most remarkable components of modern diets and their consumption has increased notably in the last few decades [6]. Although diet is one factor that can affect gut bacterial profile in early life, as well as in adulthood, the effect of fructose on gut microbiota has been poorly studied. In fact, the use of probiotics as a preventive tool has been addressed mostly in high-fat diet models. FRD has been widely used to induce MS and obesity in animal models $[7,8,11]$. Our current results show that FRD intake for six weeks was effective in inducing an increase in body weight and EAT mass. These changes were accompanied by higher Tg and LEP plasma levels, peripheral insulin-resistance and increased liver lipid content, confirming the deleterious effects caused by this diet. 
In the present study, we proposed to evaluate the potential protective effect of $L$. kefiri against the metabolic disorders induced by FRD. L. kefiri is a microorganism derived from kefir grains. Previous reports have demonstrated that kefir improves fatty liver syndrome in $o b / o b$ mice [47] and metabolic parameters in spontaneously hypertensive rats [48]. Interestingly, in our model the administration of L. kefiri completely prevented the alterations caused by FRD intake, which strongly support the beneficial effect of this probiotic. In concordance with our results, other studies have shown that the use of Lactobacillus species as probiotics improves the metabolic disorders induced by the FRD [49,50].

There is growing evidence that AT-gut microbiota axis modulates several metabolic processes, including adipokine secretion and lipid metabolism, among others [51]. For this reason, the maintenance of healthier gut microbiota is relevant for the normal function of the AT. It was demonstrated that probiotic administration to high-fat fed mice reduced the infiltration of pro-inflammatory macrophages into AT and also adipocyte size [52]. In line with these findings, our results showed that $L$. kefiri administration to FRD-fed mice decreased the expression of several pro-inflammatory cytokines in EAT, indicating a prevention of the local pro-inflammatory state caused by FRD intake. Previously, it was demonstrated that orally administered L. kefiri induces an anti-inflammatory response in the gut of healthy mice [29]. This anti-inflammatory action could lead to the prevention of body weight gain and visceral fat accumulation, as proposed as an explanation for weight modification induced by other lactobacilli [53]. Furthermore, the anti-inflammatory effect was accompanied by a partial attenuation of adipocyte hypertrophy and an improvement of insulin-sensitivity in FRD-Lk adipocytes. It is largely accepted that adipocyte size is directly correlated with LEP secretion [1]. Moreover, LEP induces the secretion of pro-inflammatory cytokines, which in turn have a positive feedback to LEP [43]. It has been reported that periodic administration of probiotic mixture to obese MSG (monosodium glutamate) rats increased adiponectin levels and decreased the leptin concentration in AT and the visceral AT mass [54]. We observed that in vitro FRD-Lk adipocytes secreted an intermediate amount of LEP between CTR and FRD adipocytes, which was in accordance with the partial recovery of adipocyte size in FRD-Lk and the decrease in inflammation. Additionally, expression analysis in EAT from FRD mice that received L. kefiri showed lower levels of $\mathrm{Ob}$, but no changes in Adipo mRNA levels compared to EAT from FRD mice. Several studies have demonstrated the beneficial effect of probiotic on lipid metabolism, by regulating the expression of lipid metabolism-related enzymes [55-57]. Specifically, a direct effect on AT lipid metabolism has been observed [58]. Our findings indicate that FRD intake generated an imbalance in the expression of lipogenic/lipolitic enzymes in EAT, that was recovered by L. kefiri administration. Overall, our results strongly support that L. kefiri treatment has several beneficial effects in AT metabolism and function, suggesting a tight communication between AT and the gut microbiota. However, further studies are needed to elucidate the mechanisms involved.

Different mediators have been proposed as a link between intestinal microbiota and host metabolism. One of these is short-chain fatty acids (SCFAs), mainly acetate, propionate and butyrate, which are generated as a result of bacterial fermentative metabolism. Due to its heterofermentative metabolism, L. kefiri produces lactic acid, ethanol and carbon dioxide as main metabolites of sugar fermentation [27]. To our knowledge, there are no scientific reports about SCFA production by L. kefiri strains. However, it is very interesting that Iraporda and coworkers recently demonstrated that lactate inhibits the activation of intestinal epithelial cells triggered by different pro-inflammatory stimuli $[59,60]$. SCFAs have been shown to generate protection against diet-induced obesity $[61,62]$. Several of their actions are mediated through activation of free fatty acid receptors (FFARs) [63], some of which are abundantly expressed in AT and may be involved in regulating lipid metabolism and glucose homeostasis [64]. Although we did not analyze the presence of lactic acid or SCFAs in fecal samples in our study, we cannot discard the hypothesis that the production of lactate or modifications in SCFA production may contribute to the preventive effect exerted by L. kefiri in our model. On the other hand, some trials suggest that another possible mechanism is a lower expression of the tight junction proteins that generates an increased gut permeability to lipopolysaccharides 
(LPS). These bacterial ligands can stimulate immune cells, such as those from AT, thus contributing to establish a chronic inflammatory state in obese individuals [41]. In fact, LPS plasma concentrations are increased in obese individuals [65], suggesting its contribution to endotoxemia and AT inflammation development during obesity.

Changes in diversity and number of bacteria in the intestinal microbiota during obesity has been proved, however, no consensus has been reached about the composition of a healthy or unhealthy gut microbiome [66]. In our studies, the PCR-DGGE assay showed that both FRD and Lk administration produced qualitative changes in the microbial community composition, while no changes in diversity were observed. Studies in animal models have shown many controversies related to Firmicutes and Bacteroidetes abundance, depending on the diet and length of treatment (high fat, high carbohydrate or high fiber diets). Some studies showed that fructose intake produces a decrease in Bacteroidetes, while others stated no changes or even an increment [49,67]. Similarly, for Firmicutes, an increase or no changes were reported $[49,50,67]$. In our study, we analyzed if both variables studied (FRD and Lk administration) affected the microbiota composition of treated mice. Firstly, we did not find any changes in Firmicutes and Bacteroidetes phyla when FRD intake was analyzed. However, we did observe a decrease in fecal Lactobacillus spp. in FRD-mice, independently if they received or not L. kefiri. This result agrees with those previously shown by Di Luccia et al. and Jena et al., who reported a decrease in Lactobacillus in high fructose-fed rats $[67,68]$. When we evaluated the effect of L. kefiri administration we observed that it has a significant positive influence in both Firmicutes and Bacteroidetes phyla, and also in two of the four specific populations studied, B. fragilis and L. murinus. All these changes evidence an effect per se of the L. kefiri strain, independent from the diet, and could be suggesting the establishment of a healthier bacterial community.

As mentioned before, most of the studies evaluating the use of probiotics have been performed in high-fat diet models. However, some works have studied the use of probiotics in high-fructose consumption models and its relationship with changes in microbiota composition. One report showed an increase in both Firmicutes and Bacteroidetes quantities in small intestine when FRD was co-administered with L. rhamnosus GG [49]. In our work, when compared group to group, a significant increase in Bacteroidetes was observed in FRD-Lk mice. On the other hand, Zhang et al. reported that FRD supplemented with L. casei, increased intestinal Bacteroides fragilis (Bacteroidetes phylum) and decreased Clostridium spp. (Firmicutes phylum) quantities, at the same time that it improved the oral glucose tolerance test in FRD-fed rats [50]. In line with these results, FRD-fed mice supplemented with L. kefiri showed an increase in B. fragilis, but no changes in Clostridium coccoides group, accompanied by an improvement of several metabolic alterations caused by FRD intake. Some reports have described beneficial effects of $B$. fragilis, including preventive effects against colitis and intestinal inflammation [69,70], and improvement in plasma levels of triglycerides and glucose [71]. Furthermore, we found that L. murinus population was higher in FRD-Lk and CTR-Lk mice. Previously, an increase of L. murinus in colon was associated with an improvement in the intestinal immunity [72]. Finally, when we analyzed Lactobacillus spp., we found a trend toward increase in CTR-Lk mice, similarly to the significant increase previously reported by our group [29]. It is worth to note that some of these results do not completely agree with Carasi et al. (2015) [29], which could be mostly related to the difference in the length of L. kefiri treatment (3 weeks vs. 6 weeks). Overall, these changes in microbiota populations may explain in part the anti-inflammatory and metabolic improvements generated by L. kefiri in Lk-treated mice. However, further studies are needed to determine the association between changes in microbiota composition, caused by L. kefiri administration, and the metabolic improvements found in our model.

\section{Conclusions}

In summary, this work showed, as expected, that a fructose-rich diet induced endocrine-metabolic alterations in mice that resemble those found in human MS. These alterations could be partially caused by a dysbiosis induced by FRD; however, more studies about effects of fructose intake on 
gut microbiota are needed. In our experimental model, we evidenced that FRD does not alter the Bacteroidetes and Firmicutes phyla, but decreases Lactobacillus spp. Moreover, we demonstrated the beneficial effects of $L$. kefiri as a probiotic, such as changing gut microbiota composition and preventing metabolic alterations and AT dysfunction induced by FRD. In this regard, we previously showed the anti-inflammatory action of L. kefiri, accordingly with a novel protective effect against AT inflammation. Finally, we have contributed to reinforce the importance of probiotics as a preventive treatment for metabolic alterations associated with obesity. In particular, the L. kefiri strain isolated from a natural food, such as kefir grains, emerges as a potential tool for obesity management.

Acknowledgments: This work was supported by grants from FONCYT (PICT-2013-0930, PICT-2015-2352 and PICT-2012-0910). Authors are grateful to Rebecca Doyle for careful manuscript editing/correction. M.d.l.A.S., P.C. and A.G. are researchers from the National Research Council of Argentina (CONICET).

Author Contributions: A.G., M.G.Z. and M.d.l.A.S. conceived and designed the experiments. M.G.Z. and S.E.G. performed research. P.C. participated in qPCR assays and analyses. M.A.R. performed the histological analysis. A.G., M.d.l.A.S., S.E.G. and M.G.Z. analyzed all data and wrote the manuscript. All the authors participated in the critical revision and correction of the final manuscript. All authors read and approved the final manuscript.

Conflicts of Interest: The authors declare no conflicts of interest.

\section{References}

1. Skurk, T.; Alberti-Huber, C.; Herder, C.; Hauner, H. Relationship between adipocyte size and adipokine expression and secretion. J. Clin. Endocrinol. Metab. 2007, 92, 1023-1033. [CrossRef] [PubMed]

2. Wåhlen, K.; Sjölin, E.; Löfgren, P. Role of fat cell size for plasma leptin in a large population based sample. Exp. Clin. Endocrinol. Diabetes 2011, 119, 291-294. [CrossRef] [PubMed]

3. Chawla, A.; Nguyen, K.D.; Goh, Y.P.S. Macrophage-mediated inflammation in metabolic disease. Nat. Rev. Immunol. 2011, 11, 738-749. [CrossRef] [PubMed]

4. Lumeng, C.N.; Bodzin, J.L.; Saltiel, A.R. Obesity induces a phenotypic switch in adipose tissue macrophage polarization. J. Clin. Investig. 2007, 117, 175-184. [CrossRef] [PubMed]

5. Marti, A.; Martinez-González, M.A.; Martinez, J.A. Interaction between genes and lifestyle factors on obesity. Proc. Nutr. Soc. 2008, 67, 1-8. [CrossRef] [PubMed]

6. Malik, V.S.; Popkin, B.M.; Bray, G.A.; Després, J.-P.; Willett, W.C.; Hu, F.B. Sugar-sweetened beverages and risk of metabolic syndrome and type 2 diabetes: A meta-analysis. Diabetes Care 2010, 33, 2477-2483. [CrossRef] [PubMed]

7. Alzamendi, A.; Zubiría, G.; Moreno, G.; Portales, A.; Spinedi, E.; Giovambattista, A. High Risk of Metabolic and Adipose Tissue Dysfunctions in Adult Male Progeny, Due to Prenatal and Adulthood Malnutrition Induced by Fructose Rich Diet. Nutrients 2016, 8, 178. [CrossRef] [PubMed]

8. Zubiría, M.G.; Fariña, J.P.; Moreno, G.; Gagliardino, J.J.; Spinedi, E.; Giovambattista, A. Excess fructose intake-induced hypertrophic visceral adipose tissue results from unbalanced precursor cell adipogenic signals. FEBS J. 2013, 280, 5864-5874. [CrossRef] [PubMed]

9. Yoo, S.; Ahn, H.; Park, Y.K. High Dietary Fructose Intake on Cardiovascular Disease Related Parameters in Growing Rats. Nutrients 2016, 9, 11. [CrossRef] [PubMed]

10. Cioffi, F.; Senese, R.; Lasala, P.; Ziello, A.; Mazzoli, A.; Crescenzo, R.; Liverini, G.; Lanni, A.; Goglia, F.; Iossa, S. Fructose-Rich Diet Affects Mitochondrial DNA Damage and Repair in Rats. Nutrients 2017, 9, 323. [CrossRef] [PubMed]

11. Zubiría, M.G.; Alzamendi, A.; Moreno, G.; Rey, M.A.; Spinedi, E.; Giovambattista, A. Long-Term Fructose Intake Increases Adipogenic Potential: Evidence of Direct Effects of Fructose on Adipocyte Precursor Cells. Nutrients 2016, 8, 198. [CrossRef] [PubMed]

12. Parks, E.J.; Skokan, L.E.; Timlin, M.T.; Dingfelder, C.S. Dietary sugars stimulate fatty acid synthesis in adults. J. Nutr. 2008, 138, 1039-1046. [PubMed]

13. Samuel, V.T. Fructose induced lipogenesis: From sugar to fat to insulin resistance. Trends Endocrinol. Metab. 2011, 22, 60-65. [CrossRef] [PubMed]

14. Gomes, A.C.; Bueno, A.A.; de Souza, R.G.; Mota, J.F. Gut microbiota, probiotics and diabetes. Nutr. J. 2014, 13, 60. [CrossRef] [PubMed] 
15. Nieuwdorp, M.; Gilijamse, P.W.; Pai, N.; Kaplan, L.M. Role of the microbiome in energy regulation and metabolism. Gastroenterology 2014, 146, 1525-3153. [CrossRef] [PubMed]

16. Vrieze, A.; Van Nood, E.; Holleman, F.; Salojärvi, J.; Kootte, R.S.; Bartelsman, J.F.W.M.; Dallinga-Thie, G.M.; Ackermans, M.T.; Serlie, M.J.; Oozeer, R.; et al. Transfer of Intestinal Microbiota From Lean Donors Increases Insulin Sensitivity in Individuals With Metabolic Syndrome. Gastroenterology 2012, 143, 913-916. [CrossRef] [PubMed]

17. Arora, T.; Singh, S.; Sharma, R.K. Probiotics: Interaction with gut microbiome and antiobesity potential. Nutrition 2013, 29, 591-596. [CrossRef] [PubMed]

18. De Oliveira Leite, A.M.; Miguel, M.A.L.; Peixoto, R.S.; Rosado, A.S.; Silva, J.T.; Paschoalin, V.M.F. Microbiological, technological and therapeutic properties of kefir: A natural probiotic beverage. Braz. J. Microbiol. 2013, 44, 341-349. [CrossRef] [PubMed]

19. Bourrie, B.C.T.; Willing, B.P.; Cotter, P.D. The Microbiota and Health Promoting Characteristics of the Fermented Beverage Kefir. Front. Microbiol. 2016, 7, 647. [CrossRef] [PubMed]

20. Nielsen, B.; Gürakan, G.C.; Unlü, G. Kefir: A multifaceted fermented dairy product. Probiotics Antimicrob. Proteins 2014, 6, 123-135. [CrossRef] [PubMed]

21. Garrote, G.L.; Delfederico, L.; Bibiloni, R.; Abraham, A.G.; Pérez, P.F.; Semorile, L.; De Antoni, G.L. Lactobacilli isolated from kefir grains: Evidence of the presence of S-layer proteins. J. Dairy Res. 2004, 71, 222-230. [CrossRef] [PubMed]

22. Hamet, M.F.; Londero, A.; Medrano, M.; Vercammen, E.; Van Hoorde, K.; Garrote, G.L.; Huys, G.; Vandamme, P.; Abraham, A.G. Application of culture-dependent and culture-independent methods for the identification of Lactobacillus kefiranofaciens in microbial consortia present in kefir grains. Food Microbiol. 2013, 36, 327-334. [CrossRef] [PubMed]

23. Golowczyc, M.A.; Mobili, P.; Garrote, G.L.; Abraham, A.G.; De Antoni, G.L. Protective action of Lactobacillus kefir carrying S-layer protein against Salmonella enterica serovar Enteritidis. Int. J. Food Microbiol. 2007, 118, 264-273. [CrossRef] [PubMed]

24. Carasi, P.; Trejo, F.M.; Pérez, P.F.; De Antoni, G.L.; Serradell, M.A. Surface proteins from Lactobacillus kefir antagonize in vitro cytotoxic effect of Clostridium difficile toxins. Anaerobe 2012, 18, 135-142. [CrossRef] [PubMed]

25. Carey, C.M.; Kostrzynska, M. Lactic acid bacteria and bifidobacteria attenuate the proinflammatory response in intestinal epithelial cells induced by Salmonella enterica serovar Typhimurium. Can. J. Microbiol. 2013, 59, 9-17. [CrossRef] [PubMed]

26. Hong, W.S.; Chen, H.C.; Chen, Y.P.; Chen, M.J. Effects of kefir supernatant and lactic acid bacteria isolated from kefir grain on cytokine production by macrophage. Int. Dairy J. 2009, 19, 244-251. [CrossRef]

27. Carasi, P. Potencialidad Probiótica de Lactobacilos con Capa S. Estudios sobre la inocuidad, efecto antimicrobiano y capacidad inmunomodulatoria de Lactobacillus kefiri. Ph.D. Thesis, United Nations Laissez-Passer (UNLP), La Plata, Argentina, 2014.

28. Carasi, P.; Díaz, M.; Racedo, S.M.; De Antoni, G.; Urdaci, M.C.; Serradell, M.A. Safety Characterization and Antimicrobial Properties of Kefir-Isolated Lactobacillus kefiri. BioMed Res. Int. 2014, 2014, 208974. [CrossRef] [PubMed]

29. Carasi, P.; Racedo, S.M.; Jacquot, C.; Romanin, D.E.; Serradell, M.A.; Urdaci, M.C. Impact of kefir derived Lactobacillus kefiri on the mucosal immune response and gut microbiota. J. Immunol. Res. 2015, 2015, 361604. [CrossRef] [PubMed]

30. Garrote, G.L.; Abraham, A.G.; De Antoni, G.L. Chemical and microbiological characterisation of kefir grains. J. Dairy Res. 2001, 68, 639-652. [CrossRef] [PubMed]

31. Perelló, M.; Gaillard, R.C.; Chisari, A.; Spinedi, E. Adrenal enucleation in MSG-damaged hyperleptinemic male rats transiently restores adrenal sensitivity to leptin. Neuroendocrinology 2003, 78, 176-184. [CrossRef] [PubMed]

32. Giovambattista, A.; Gaillard, R.C.; Spinedi, E. Ghrelin gene-related peptides modulate rat white adiposity. Vitam. Horm. 2008, 77, 171-205. [PubMed]

33. Alzamendi, A.; Giovambattista, A.; García, M.E.; Rebolledo, O.R.; Gagliardino, J.J.; Spinedi, E. Effect of pioglitazone on the fructose-induced abdominal adipose tissue dysfunction. PPAR Res. 2012, 2012, 259093. [CrossRef] [PubMed]

34. Alzamendi, A.; Castrogiovanni, D.; Gaillard, R.C.; Spinedi, E.; Giovambattista, A. Increased male offspring's risk of metabolic-neuroendocrine dysfunction and overweight after fructose-rich diet intake by the lactating mother. Endocrinology 2010, 151, 4214-4223. [CrossRef] [PubMed] 
35. Giovambattista, A.; Piermaría, J.; Suescun, M.O.; Calandra, R.S.; Gaillard, R.C.; Spinedi, E. Direct effect of ghrelin on leptin production by cultured rat white adipocytes. Obesity 2006, 14, 19-27. [CrossRef] [PubMed]

36. Malinen, E.; Kassinen, A.; Rinttilä, T.; Palva, A. Comparison of real-time PCR with SYBR Green I or 5 -nuclease assays and dot-blot hybridization with rDNA-targeted oligonucleotide probes in quantification of selected faecal bacteria. Microbiology 2003, 149, 269-277. [CrossRef] [PubMed]

37. Muyzer, G.; de Waal, E.C.; Uitterlinden, A.G. Profiling of complex microbial populations by denaturing gradient gel electrophoresis analysis of polymerase chain reaction-amplified genes coding for 16S rRNA. Appl. Environ. Microbiol. 1993, 59, 695-700. [PubMed]

38. Cocolin, L.; Alessandria, V.; Botta, C.; Gorra, R.; De Filippis, F.; Ercolini, D.; Rantsiou, K. NaOH-debittering induces changes in bacterial ecology during table olives fermentation. PLoS ONE 2013, 8, e69074. [CrossRef] [PubMed]

39. Pavel, A.B.; Vasile, C.I. PyElph-A software tool for gel images analysis and phylogenetics. BMC Bioinform. 2012, 13, 9. [CrossRef] [PubMed]

40. Cani, P.D.; Delzenne, N.M. The role of the gut microbiota in energy metabolism and metabolic disease. Curr. Pharm. Des. 2009, 15, 1546-1558. [CrossRef] [PubMed]

41. Drissi, F.; Raoult, D.; Merhej, V. Metabolic role of lactobacilli in weight modification in humans and animals. Microb. Pathog. 2016. [CrossRef] [PubMed]

42. Tilg, H.; Kaser, A. Gut microbiome, obesity, and metabolic dysfunction. J. Clin. Investig. 2011, 121, $2126-2132$. [CrossRef] [PubMed]

43. Harper, J.W.; Zisman, T.L. Interaction of obesity and inflammatory bowel disease. World J. Gastroenterol. 2016, 22, 7868. [CrossRef] [PubMed]

44. Vieira, L.Q.; dos Santos, L.M.; Neumann, E.; da Silva, A.P.; Moura, L.N.; Nicoli, J.R. Probiotics Protect Mice Against Experimental Infections. J. Clin. Gastroenterol. 2008, 42, S168-S169. [CrossRef] [PubMed]

45. Lebeer, S.; Vanderleyden, J.; De Keersmaecker, S.C.J. Genes and molecules of lactobacilli supporting probiotic action. Microbiol. Mol. Biol. Rev. 2008, 72, 728-764. [CrossRef] [PubMed]

46. Xu, R.-Y.; Wan, Y.-P.; Fang, Q.-Y.; Lu, W.; Cai, W. Supplementation with probiotics modifies gut flora and attenuates liver fat accumulation in rat nonalcoholic fatty liver disease model. J. Clin. Biochem. Nutr. 2012, 50, 72-77. [CrossRef] [PubMed]

47. Chen, H.-L.; Tung, Y.-T.; Tsai, C.-L.; Lai, C.-W.; Lai, Z.-L.; Tsai, H.-C.; Lin, Y.-L.; Wang, C.-H.; Chen, C.-M. Kefir improves fatty liver syndrome by inhibiting the lipogenesis pathway in leptin-deficient $o b / o b$ knockout mice. Int. J. Obes. 2014, 38, 1172-1179. [CrossRef] [PubMed]

48. Rosa, D.D.; Grześkowiak, Ł.M.; Ferreira, C.L.L.F.; Fonseca, A.C.M.; Reis, S.A.; Dias, M.M.; Siqueira, N.P.; Silva, L.L.; Neves, C.A.; Oliveira, L.L.; et al. Kefir reduces insulin resistance and inflammatory cytokine expression in an animal model of metabolic syndrome. Food Funct. 2016, 7, 3390-3401. [CrossRef] [PubMed]

49. Ritze, Y.; Bárdos, G.; Claus, A.; Ehrmann, V.; Bergheim, I.; Schwiertz, A.; Bischoff, S.C. Lactobacillus rhamnosus GG protects against non-alcoholic fatty liver disease in mice. PLoS ONE 2014, 9, e80169. [CrossRef] [PubMed]

50. Zhang, Y.; Wang, L.; Zhang, J.; Li, Y.; He, Q.; Li, H.; Guo, X.; Guo, J.; Zhang, H. Probiotic Lactobacillus casei Zhang ameliorates high-fructose-induced impaired glucose tolerance in hyperinsulinemia rats. Eur. J. Nutr. 2014, 53, 221-232. [CrossRef] [PubMed]

51. Machado, M.; Cortez-Pinto, H. Diet, Microbiota, Obesity, and NAFLD: A Dangerous Quartet. Int. J. Mol. Sci. 2016, 17, 481. [CrossRef] [PubMed]

52. Wang, J.; Tang, H.; Zhang, C.; Zhao, Y.; Derrien, M.; Rocher, E.; van-Hylckama Vlieg, J.E.; Strissel, K.; Zhao, L.; Obin, M.; et al. Modulation of gut microbiota during probiotic-mediated attenuation of metabolic syndrome in high fat diet-fed mice. ISME J. 2015, 9, 1-15. [CrossRef] [PubMed]

53. Miyoshi, M.; Ogawa, A.; Higurashi, S.; Kadooka, Y. Anti-obesity effect of Lactobacillus gasseri SBT2055 accompanied by inhibition of pro-inflammatory gene expression in the visceral adipose tissue in diet-induced obese mice. Eur. J. Nutr. 2014, 53, 599-606. [CrossRef] [PubMed]

54. Savcheniuk, O.A.; Virchenko, O.V.; Falalyeyeva, T.M.; Beregova, T.V.; Babenko, L.P.; Lazarenko, L.M.; Demchenko, O.M.; Bubnov, R.V.; Spivak, M.Y. The efficacy of probiotics for monosodium glutamate-induced obesity: Dietology concerns and opportunities for prevention. EPMA J. 2014, 5, 2. [CrossRef] [PubMed]

55. Kim, B.; Park, K.-Y.; Ji, Y.; Park, S.; Holzapfel, W.; Hyun, C.-K. Protective effects of Lactobacillus rhamnosus GG against dyslipidemia in high-fat diet-induced obese mice. Biochem. Biophys. Res. Commun. 2016, 473, 530-536. [CrossRef] [PubMed] 
56. Wang, Y.; Xu, N.; Xi, A.; Ahmed, Z.; Zhang, B.; Bai, X. Effects of Lactobacillus plantarum MA2 isolated from Tibet kefir on lipid metabolism and intestinal microflora of rats fed on high-cholesterol diet. Appl. Microbiol. Biotechnol. 2009, 84, 341-347. [CrossRef] [PubMed]

57. Kawase, M.; Hashimoto, H.; Hosoda, M.; Morita, H.; Hosono, A. Effect of administration of fermented milk containing whey protein concentrate to rats and healthy men on serum lipids and blood pressure. J. Dairy Sci. 2000, 83, 255-263. [CrossRef]

58. Cui, C.; Shen, C.J.; Jia, G.; Wang, K.N. Effect of dietary Bacillus subtilis on proportion of Bacteroidetes and Firmicutes in swine intestine and lipid metabolism. Genet. Mol. Res. 2013, 12, 1766-1776. [CrossRef] [PubMed]

59. Iraporda, C.; Romanin, D.E.; Rumbo, M.; Garrote, G.L.; Abraham, A.G. The role of lactate on the immunomodulatory properties of the nonbacterial fraction of kefir. Food Res. Int. 2014, 62, 247-253. [CrossRef]

60. Iraporda, C.; Errea, A.; Romanin, D.E.; Cayet, D.; Pereyra, E.; Pignataro, O.; Sirard, J.C.; Garrote, G.L.; Abraham, A.G.; Rumbo, M. Lactate and short chain fatty acids produced by microbial fermentation downregulate proinflammatory responses in intestinal epithelial cells and myeloid cells. Immunobiology 2015, 220, 1161-1169. [CrossRef] [PubMed]

61. Gao, Z.; Yin, J.; Zhang, J.; Ward, R.E.; Martin, R.J.; Lefevre, M.; Cefalu, W.T.; Ye, J. Butyrate Improves Insulin Sensitivity and Increases Energy Expenditure in Mice. Diabetes 2009, 58, 1509-1517. [CrossRef] [PubMed]

62. Lin, H.V.; Frassetto, A.; Kowalik, E.J.; Nawrocki, A.R.; Lu, M.M.; Kosinski, J.R.; Hubert, J.A.; Szeto, D.; Yao, X.; Forrest, G.; et al. Butyrate and propionate protect against diet-induced obesity and regulate gut hormones via free fatty acid receptor 3-independent mechanisms. PLoS ONE 2012, 7, e35240. [CrossRef] [PubMed]

63. Ichimura, A.; Hasegawa, S.; Kasubuchi, M.; Kimura, I. Free fatty acid receptors as therapeutic targets for the treatment of diabetes. Front. Pharmacol. 2014, 5, 236. [CrossRef] [PubMed]

64. Kimura, I.; Ozawa, K.; Inoue, D.; Imamura, T.; Kimura, K.; Maeda, T.; Terasawa, K.; Kashihara, D.; Hirano, K.; Tani, T.; et al. The gut microbiota suppresses insulin-mediated fat accumulation via the short-chain fatty acid receptor GPR43. Nat. Commun. 2013, 4, 1829. [CrossRef] [PubMed]

65. Boutagy, N.E.; McMillan, R.P.; Frisard, M.I.; Hulver, M.W. Metabolic endotoxemia with obesity: Is it real and is it relevant? Biochimie 2016, 124, 11-20. [CrossRef] [PubMed]

66. Payne, A.N.; Chassard, C.; Lacroix, C. Gut microbial adaptation to dietary consumption of fructose, artificial sweeteners and sugar alcohols: Implications for host-microbe interactions contributing to obesity. Obes. Rev. 2012, 13, 799-809. [CrossRef] [PubMed]

67. Di Luccia, B.; Crescenzo, R.; Mazzoli, A.; Cigliano, L.; Venditti, P.; Walser, J.-C.; Widmer, A.; Baccigalupi, L.; Ricca, E.; Iossa, S. Rescue of Fructose-Induced Metabolic Syndrome by Antibiotics or Faecal Transplantation in a Rat Model of Obesity. PLoS ONE 2015, 10, e0134893. [CrossRef] [PubMed]

68. Jena, P.K.; Singh, S.; Prajapati, B.; Nareshkumar, G.; Mehta, T.; Seshadri, S. Impact of targeted specific antibiotic delivery for gut microbiota modulation on high-fructose-fed rats. Appl. Biochem. Biotechnol. 2014, 172, 3810-3826. [CrossRef] [PubMed]

69. Mazmanian, S.K.; Round, J.L.; Kasper, D.L. A microbial symbiosis factor prevents intestinal inflammatory disease. Nature 2008, 453, 620-625. [CrossRef] [PubMed]

70. Mazmanian, S.K.; Liu, C.H.; Tzianabos, A.O.; Kasper, D.L. An immunomodulatory molecule of symbiotic bacteria directs maturation of the host immune system. Cell 2005, 122, 107-118. [CrossRef] [PubMed]

71. Haro, C.; Garcia-Carpintero, S.; Alcala-Diaz, J.F.; Gomez-Delgado, F.; Delgado-Lista, J.; Perez-Martinez, P.; Rangel Zuñiga, O.A.; Quintana-Navarro, G.M.; Landa, B.B.; Clemente, J.C.; et al. The gut microbial community in metabolic syndrome patients is modified by diet. J. Nutr. Biochem. 2016, 27, 27-31. [CrossRef] [PubMed]

72. Tang, C.; Kamiya, T.; Liu, Y.; Kadoki, M.; Kakuta, S.; Oshima, K.; Hattori, M.; Takeshita, K.; Kanai, T.; Saijo, S.; et al. Inhibition of Dectin-1 Signaling Ameliorates Colitis by Inducing Lactobacillus-Mediated Regulatory $\mathrm{T}$ Cell Expansion in the Intestine. Cell Host Microbe 2015, 18, 183-197. [CrossRef] [PubMed]

(C) 2017 by the authors. Licensee MDPI, Basel, Switzerland. This article is an open access article distributed under the terms and conditions of the Creative Commons Attribution (CC BY) license (http:/ / creativecommons.org/licenses/by/4.0/). 